\title{
Co-expression of the carbamoyl-phosphate synthase 1 gene and its long non-coding RNA correlates with poor prognosis of patients with intrahepatic cholangiocarcinoma
}

\author{
SEN-LIN MA ${ }^{1}$, AI-JUN LI ${ }^{1}$, ZHAO-YANG HU ${ }^{2}$, FU-SHENG SHANG ${ }^{3}$ and MENG-CHAO WU ${ }^{1}$ \\ ${ }^{1}$ Department of Second Special Treatment, Eastern Hepatobiliary Surgery Hospital, Second Military Medical University, \\ Shanghai 200438; ${ }^{2}$ Tumor Research Institute, Hangzhou Cancer Hospital, Hangzhou, Zhejiang 310002; \\ ${ }^{3}$ Department of Experiments, Shanghai Fu Neng Biological Technology Co., Ltd., Shanghai 200237, P.R. China
}

Received February 25, 2015; Accepted September 1, 2015

DOI: $10.3892 / \mathrm{mmr} .2015 .4435$

\begin{abstract}
The mechanisms leading to high rates of malignancy and recurrence of human intrahepatic cholangiocarcinoma (ICC) remain unclear. It is difficult to diagnose and assess the prognosis of patients with ICC in the clinic due to the lack of specific biomarkers. In addition, long non-coding RNAs (lncRNAs) have been reported to serve important roles in certain types of tumorigenesis however a role in ICC remains to be reported. The aim of the current study was to screen for genes and lncRNAs that are abnormally expressed in ICC and to investigate their biological and clinicopathological significance in ICC. The global gene and lncRNA expression profiles in ICC were measured using bioinformatics analysis. Carbamoyl-phosphate synthase 1 (CPS1) and its lncRNA CPS1 intronic transcript 1 (CPS1-IT1) were observed to be upregulated in ICC. The expression of CPS1 and CPS1-IT1 was measured in 31 tissue samples from patients with ICC and a number of cell lines. The effects of CPS1 and CPS1-IT1 on the proliferation and apoptosis of the ICC-9810 cell line were measured. In addition, the clinicopathological features and survival rates of patients with ICC with respect to the gene and lncRNA expression status were analyzed. CPS1 and CPS1-IT1 were co-upregulated in ICC tissues compared with non-cancerous tissues. Knockdown of CPS1 andor CPS1-IT1 reduced the proliferation and increased the apoptosis of ICC-9810 cells. Additionally, clinical analysis indicated that CPS1 and CPS1-IT1 were associated with poor liver function and reduced survival rates when the relative expression values were greater than 4 in cancer tissues. The comparisons between the high CPS1 expression group and the low expression group
\end{abstract}

Correspondence to: Professor Ai-Jun Li, Department of Second Special Treatment, Eastern Hepatobiliary Surgery Hospital, Second Military Medical University, 225 Changhai Road, Shanghai 200438, P.R. China

E-mail: aijunlihappy@163.com

Key words: CPS1, CPS1-IT1, lncRNA, ICC, prognosis indicated significant differences in international normalized ratio $(\mathrm{P}=0.048)$, total protein $(\mathrm{P}=0.049)$, indirect bilirubin $(\mathrm{P}=0.025)$, alkaline phosphatase $(\mathrm{P}=0.003)$ and disease-free survival $(\mathrm{P}=0.034)$. In addition, there were differential trends in CA19-9 $(\mathrm{P}=0.068)$, globulin $(\mathrm{P}=0.052)$ and total bilirubin $(\mathrm{P}=0.066)$. The comparisons between the high CPS1-IT1 expression group and the low expression group indicated significant differences in lymphatic invasion $(\mathrm{P}=0.045)$, carbohydrate antigen $19-9(\mathrm{P}=0.044)$, disease-free survival $(\mathrm{P}=0.026)$, and non-significant differential trends in alkaline phosphatase were observed $(\mathrm{P}=0.085)$. In conclusion, CPS1 and CPS1-IT1 may serve an important role in ICC development by promoting the proliferation of ICC cells. Furthermore, CPS1 and CPS1-IT1 were associated with poor liver function and reduced survival rates. Thus, CPS1 and CPS1-IT1 may be potential prognostic indicators for patients with ICC.

\section{Introduction}

Intrahepatic cholangiocarcinoma (ICC) originates directly from intrahepatic biliary epithelial cells and additionally from the transdifferentiation of hepatocytes $(1,2)$. ICC is highly malignant and the incidence has increased over the recent decades (3-5). The incidence of ICC, which varies substantially worldwide, is approximately $15 \%$ of all cases of primary liver cancer $(6,7)$. Currently, surgical excision is considered the only possible curative treatment for early stage patients with ICC. However, fewer than $40 \%$ of all patients are eligible for surgery due to non-specific clinical presentation and the current lack of effective diagnostic systems for ICC (8-10). In addition, the surgical prognosis for patients with ICC is poor, with a recurrence rate of $60 \%$ and a median disease-free survival of 26 months (11-13).

The mechanisms leading to high-grade malignancy and recurrence rates remain unclear (14). Although the 7 th Edition Staging Manual of the American Joint Committee on Cancer for ICC is relatively new, clear associations between the clinicopathological features and prognosis remain unclear (15). Thus, studies on the pathogenesis and prognosis of ICC are gaining interest worldwide. 
Long non-coding RNAs (lncRNAs) are RNA molecules greater than 200 nucleotides in length and have been determined to serve various important roles in tumorigenesis $(16,17)$. For instance, differential display code 3 , a prostate cancer-specific lncRNA, may be detected in urine and used for the early diagnosis of prostate cancer $(18,19)$. Metastasis-associated lung adenocarcinoma transcript 1 is a potential diagnostic biomarker in addition to being a potential prognostic biomarker that is upregulated in metastatic non-small cell lung carcinoma, breast cancer, pancreatic cancer and prostate cancer $(20,21)$. In addition, the expression of HOX transcript antisense RNA and H19 is associated with various types of tumor $(22,23)$. However, the mechanisms by which lncRNAs contribute to ICC remain to be fully elucidated.

In the present study, the expression profiles of genes and lncRNAs in ICC were analyzed using bioinformatics. This indicated that carbamoyl-phosphate synthase 1 (CPS1) and its lncRNA, CPS1 intronic transcript 1 (CPS1-IT1), are significantly co-upregulated. CPS1 is a gene in $2 \mathrm{q} 34$ of the human chromosome and encodes the CPS1 protein, which is the first key enzyme in the urea cycle (http://www.genecards.org/cgi-bin/carddisp. pl?gene $=\mathrm{CPS} 1 \&$ keywords $=\mathrm{cps} 1$ ). Deficiencies in CPS1 can result in brain damage, coma or other central nervous system dysfunctions (24). CPS1-IT1 is a 2,306-base RNA molecule transcribed by the CPS1 gene from 211,482,295-211,484,600 base pairs (http://www.genecards.org/cgi-bin/carddisp.pl?gene= CPS1-IT1\&keywords=CPS1-IT1). The roles of CPS1 and CPS1-IT1 in ICC remain to be fully elucidated, therefore were investigated in the current study.

\section{Materials and methods}

Patients and specimens. A total of 31 patients with ICC who underwent surgery at the Eastern Hepatobiliary Surgery Hospital, Second Military Medical University (Shanghai, China) between 2011 and 2013 were enrolled in the current study. All patients underwent a resection of the primary cancer. No patients received chemotherapy or radiotherapy prior to or following surgery. The resected cancer tissues and non-tumorous tissues specimens were immediately frozen in liquid nitrogen and maintained at $-80^{\circ} \mathrm{C}$ until the extraction of RNA, immunohistochemistry, and immunofluorescence were conducted. Written informed consent was obtained from all patients. The follow-up ranged from 1-35 months with a median of 18 months.

Reverse transcription-quantitative polymerase chain reaction (RT-qPCR) detection of CPS1 mRNA and CPS1-IT1. RT-qPCR is the gold standard for the quantification of DNA and RNA. cDNA was generated using the GoScript Reverse Transcription System (Qiagen GmbH, Hilden, Germany) from $1 \mu \mathrm{g}$ RNA. qPCR was conducted using the GoTaq qPCR Master Mix (Qiagen $\mathrm{GmbH}$ ) with an Mx3005P qPCR System (Agilent Technologies, Inc., Santa Clara, CA, USA). The sequences of the PCR primers used were as follows: CPS1, sense 5'-TTTAGG GCAATGGCTACAGG-3' and antisense 5'-GTTCTGCAA GAGCTGGGTTC-3'; CPS1-IT1, sense 5'-CACAGATGATCC ACGGCGTT-3' and antisense 5'-GCGTGCATCAATGACACT TCA-3'; GAPDH, sense 5'-CGGAGTCAACGGATTTGGTCG TATTGG-3' and antisense 5'-GCTCCTGGAAGATGGTGA TGGGATTTCC-3'; u6, sense 5'-CTCGCTTCGGCAGCA
CA-3' and antisense 5'-AATGCTATCACCTCCCCTGTGT-3'. The data were analyzed using the $\Delta \mathrm{Ct}$ method or $2^{-\Delta \Delta \mathrm{Ct}}(25,26)$. All data were presented as the mean \pm standard deviation of three independent experiments.

Cell culture. The L-02 normal human liver cell line and the Huh-7 and Bel-7402 cell lines were provided by the Cell Bank of Type Culture Collection of Chinese Academy of Sciences (Shanghai, China). The ICC-9810, HepG2 and MHCC-97L cells lines were provided by the Second Military Medical University (Shanghai, China). Cells were maintained in RPMI 1640 medium containing $10 \%$ fetal bovine serum (FBS; Invitrogen Life Technologies) and penicillin/streptomycin (GE Healthcare Life Sciences, Logan, UT, USA) at $37^{\circ} \mathrm{C}$ in a humidified $5 \% \mathrm{CO}_{2}$ atmosphere (27).

CPS1 and CPS1-IT1 RNA interference (RNAi). CPS1-specific siRNA (Silencer ${ }^{\mathrm{TM}}$ Predesigned siRNA; sense GCAGCA UUGACCUAGUGAUTT and antisense AUCACUAGGUCA AUGCUCGCTT), CPS1-IT1-specific siRNA (Silencer ${ }^{\mathrm{TM}}$ Predesigned siRNA; sense CGAGUUCUAAAGUCCGAUATT and antisense UAUCGGACUUUAGAACUCGTT) and negative control siRNA (Silencer ${ }^{\mathrm{TM}}$ Negative Control siRNA) were purchased from Life Technologies (Grand Island, NY, USA). The ICC-9810 cells were assigned to the following treatment groups: A siCPS1 group, a siCPS1-IT1 group, a siCPS1 + siCPS1-IT1 group, and a negative control siRNA group. The ICC-9810 cells were cultured overnight until they were $80 \%$ adherent. siRNA oligomers were diluted with Opti-MEM ${ }^{\circledR}$ I Reduced Serum medium (Invitrogen Life Technologies, Carlsbad, CA, USA) and incubated for $5 \mathrm{~min}$ at room temperature. The siRNA oligomers (final concentration, $20 \mathrm{nmol}$ ) were mixed with the Lipofectamine ${ }^{\circledR} 2000$ (7.5 ml/well; Invitrogen; Thermo Fisher Scientific, Inc., Waltham, MA, USA) and incubated for $20 \mathrm{~min}$ at room temperature to allow siRNA-Lipofectamine ${ }^{\circledR} 2000$ complexes to form. The siRNA-Lipofectamine ${ }^{\circledR} 2000$ complexes were added to each well at a final concentration of 50 pmolml. The cells were incubated in a humidified atmosphere $\left(37^{\circ} \mathrm{C}\right.$ and $5 \% \mathrm{CO}_{2}$ ) and the RPMI-1640 medium supplemented with $10 \%$ FBS was replaced following $4 \mathrm{~h}$.

Immunohistochemistry and immunofluorescence. Following rinsing with Paraplast ${ }^{\circledR}$ Tissue Embedding Medium (Leica Microsystems GmbH, Wetzlar, Germany), tissue specimens from patients with ICC were embedded in paraffin (Leica Microsystems $\mathrm{GmbH}$ ), prior to being cut (4 $\mu \mathrm{m}$ thick) for immunohistochemistry using a microtome (RM2265; Leica Microsystems $\mathrm{GmbH}$ ). Deparaffinization was conducted by treating the cells with xylene for $10 \mathrm{~min}$; $100 \%$ ethanol for $1 \mathrm{~min}$, $95 \%$ ethanol for $1 \mathrm{~min}, 85 \%$ ethanol for $1 \mathrm{~min}$, and $75 \%$ ethanol for 1 min (Shanghai Chemical Reagent Co., Ltd., Shanghai, China). Endogenous peroxidase activity was then blocked using $0.3 \% \mathrm{H}_{2} \mathrm{O}_{2}$ in methanol (Shanghai Chemical Reagent Co., Ltd., Shanghai, China) for $30 \mathrm{~min}$ following deparaffinization. Antigen retrieval was conducted using antigen unmasking solution (Vector Laboratories, Inc., Burlingame, CA, USA) and microwaving at medium/high heat for $15 \mathrm{~min}$, keeping the solution boiling, followed by treatment with 5\% skimmed milk in phosphate-buffered saline (PBS)-0.1\% bovine serum albumin [Bioengineering (Shanghai) Ltd., Shanghai, China] for 
a minimum of $1 \mathrm{~h}$ at room temperature to block nonspecific staining.

The slides were incubated with antibodies targeting rabbit polyclonal CPS1 (1:1,000; cat. no. ab45956; Abcam, Cambridge, UK) at $4^{\circ} \mathrm{C}$ overnight. Sections were incubated with secondary antibodies (MP-7401; Vector Laboratories, Inc., Burlingame, $\mathrm{CA}, \mathrm{USA}$ ) at $37^{\circ} \mathrm{C}$ for $1 \mathrm{~h}$, and visualization of antigen-antibody reactions was achieved using 3,3'-diaminobenzidine (SK-4100; Vector Laboratories, Inc.). Tissue structures were visualized by counterstaining with hematoxylin [Bioengineering (Shanghai) Ltd.].

For immunofluorescence, $5-\mu \mathrm{m}$ frozen sections were cut using Cryocut (CM1850; Leica Microsystems Gmbh) and fixed in ice-cold acetone-methanol (1:1; Shanghai Chemical Reagent Co., Ltd.) for $30 \mathrm{~min}$ on ice. The slides were then incubated with rabbit monoclonal anti-Ki67 (Novus, 1:4,000; cat. no. ab16667; Abcam) in Tris-buffered saline with Tween-20 [Bioengineering (Shanghai) Ltd.] containing $5 \%$ non-fat dried milk at $4^{\circ} \mathrm{C}$ overnight. Following three washes in PBS, the primary antibody was detected using a fluorescein isothiocyanate-conjugated goat anti-rabbit IgG secondary antibody (cat. no. ab6717; Molecular Probes Life Technologies, Carlsbad, CA, USA) at $37^{\circ} \mathrm{C}$ for $1 \mathrm{~h}$. The sections were stained for 2 min with DAPI (D21490; Thermo Fisher Scientific, Inc.) following three washes with PBS. Sections were imaged using a Zeiss Axioskop (Zeiss, Oberkochen, Germany) fluorescence microscope equipped with a charge coupled device imaging system and Calypso 4.0 software (Zeiss) as previously described (28).

Western blotting. The cells or tissue samples were lysed in lysis buffer containing $250 \mathrm{mM} \mathrm{NaCl}, 1 \%$ NP-40, $50 \mathrm{mM}$ Tris-HCL ( $\mathrm{pH}$ 7.4) and $0.5 \%$ sodium deoxycholate [Bioengineering (Shanghai) Ltd., Shanghai, China]. The samples were then subjected to centrifugation at $18,894 \mathrm{x}$ g for $15 \mathrm{~min}$ at $4^{\circ} \mathrm{C}$. The protein samples were loaded onto $10 \%$ SDS-PAGE prior to being electrotransferred onto polyvinylidene difluoride membranes (EMD Millipore, Billerica, MA, USA) as previously described (29). Following blocking with skimmed milk (Nestle (China), Ltd., Beijing China), the membranes were incubated with primary antibodies targeting rabbit polyclonal anti-CPS1 (cat. no ab45956; Abcam) at $4^{\circ} \mathrm{C}$ overnight. The membranes were then washed three times and incubated with horseradish peroxidase-conjugated goat anti-rabbit $\operatorname{IgG}$ secondary antibodies (cat. no. ab6721; Abcam) at room temperature for $40 \mathrm{~min}$. The chemiluminescent signal was detected using a Chemiluminescence Imaging system (ChemiScope 3600 Mini; Clinx, Shanghai, China).

In vitro proliferation assay. Cell proliferation and viability were assessed using the Cell Counting Kit-8 (CCK8, Dojindo Molecular Technologies, Inc., Kumamoto, Japan) according to the manufacturer's instructions. The cells from the siCPS1, siCPS1-IT1, siCPS1 + siCPS1-IT1 and the control (scramble) groups were seeded at a density of 2,000 cells/well on 96-well plates and cultured in $5 \% \mathrm{CO}_{2}$ at $37^{\circ} \mathrm{C}$ for $24 \mathrm{~h}$. The media was replaced every $24 \mathrm{~h}$. Subsequently, CCK8 was added and the plates were incubated for $2 \mathrm{~h}$. Absorbance (A) was read at $450 \mathrm{~nm}$ using a microplate reader (Multiskan FC; Thermo Fisher Scientific, Inc.) and the percentage cell viability was calculated based on the following formula: Cell viability $(\%)=[\mathrm{A}($ dose $)-\mathrm{A}($ blank $)][(\mathrm{A}(0$ dose $)-\mathrm{A}($ blank $)] \times 100$. Proliferation was measured in all groups at 24, 48, 72 and $96 \mathrm{~h}$ following the addition of siRNA as previously described (30).

Flow cytometric analysis. The cells from the siCPS1, siCPS1-IT1, siCPS1 + siCPS1-IT1 and the negative control siRNA groups were seeded into 6-well plates at a density of $1 \times 10^{5}$ cells/well with RPMI-1640 medium, harvested and rinsed twice using PBS. Following centrifugation at $112 \mathrm{x} \mathrm{g}$ and $4^{\circ} \mathrm{C}$ for $5 \mathrm{~min}$, the cells were resuspended in $100 \mu \mathrm{l}$ binding buffer [Bioengineering (Shanghai) Ltd.]. Dissociated cells were stained with $5 \mu \mathrm{l}$ Annexin $\mathrm{V}$ and $5 \mu \mathrm{l}$ propidium iodide (BD 55654; BD Biosciences, San Jose, CA, USA) for $20 \mathrm{~min}$ at room temperature. Cells (10,000/sample) were collected and analyzed using a FACScan flow cytometer (BD Biosciences). The data were analyzed with CellQuest software (BD Biosciences).

Bioinformatics analysis. The human genes and lncRNAs microarray was conducted using the genechip Affymetrix Human Genome U133 Plus 2.0 Array (GEO accession number, GPL570; Affymetrix, Inc., Santa Clara, CA, USA). Intrahepatic cholangiocarcinoma gene and lncRNA expression data used in the present study were obtained from the Gene Expression Omnibus (GEO) database (http://www.ncbi. nlm.nih.gov/geo/query/acc.cgi?acc=GSE32958). The data resource was detected using GeneChip ${ }^{\circledR}$ Human Genome U133 Plus 2.0 Array (Affymetrix, San Francisco, CA, USA). The gene chip contains 54,676 probes. It can analyze the mRNA levels of 19,850 genes and the expression data of 5,635 lncRNAs (31). The raw CEL files were downloaded, the quantile was normalized and the background adjusted $(32,33)$. The differential factors in intrahepatic cholangiocarcinoma were screened using R (version 3.1.0) AFFY program package (Auckland University, Auckland, New Zealand). Log2 (fold change) $>1$ represents upregulation of genes or lncRNAs, $\log 2$ (fold change) $<1$ represents downregulation of genes or lncRNAs (34). In addition, $\mathrm{P}<0.01$ was considered to indicate a statistically significant difference. Significantly differentially expressed genes and lncRNAs were extracted by volcano plot analysis with the filtering criteria of a 10.0-fold change and $\mathrm{P}<0.01$ using GeneSpring GX software, version 7.3 (Agilent Technologies, Inc., Santa Clara, CA, USA).

Statistical analysis. The continuous variables were expressed as the mean \pm standard deviation. The association between the expression of CPS1 and CPS1-IT1 and the clinicopathological factors and in vitro assay data were analyzed using Student's $\mathrm{t}$-test, the Mann-Whitney U test and repeated measures analysis of variance. The overall survival curves and disease-free survival curves were plotted according to the Kaplan-Meier method measured from the day of surgery to the end of follow-up. The log-rank test was used for the comparison of survival data. $\mathrm{P}<005$ was considered to indicate a statistically significant difference. Statistical analysis was performed using SPSS software, version 19.0 (IBM SPSS, Armonk, NY, USA).

\section{Results}

CPS1 and CPS1-IT1 are co-expressed in ICC tissue. The expression of human genes and lncRNAs were analyzed in ICC 
Table I. Genes and lncRNAs with the most significantly different expression levels between intrahepatic cholangiocarcinoma and non-tumorous tissues assessed by bioinformatics analysis.

\begin{tabular}{|c|c|c|c|c|}
\hline Gene/lncRNA & Tumor & Non-tumor & Log2 (fold change) & P-value \\
\hline NR1I3 & 34.40 & 39.04 & 4.80 & $8.93 \times 10^{-22}$ \\
\hline CYP2A13 & 32.93 & 38.15 & 5.81 & $2.47 \times 10^{-21}$ \\
\hline HGFAC & 32.76 & 37.67 & 3.37 & $4.29 \times 10^{-21}$ \\
\hline CYP4A22 & 31.74 & 37.40 & 4.78 & $5.82 \times 10^{-21}$ \\
\hline FAM99A & 29.92 & 36.17 & 4.76 & $2.28 \times 10^{-20}$ \\
\hline CPS1-IT1 & 29.57 & 35.92 & 5.42 & $3.00 \times 10^{-20}$ \\
\hline HAO2 & 28.55 & 35.19 & 5.80 & $6.73 \times 10^{-20}$ \\
\hline APOF & 27.67 & 34.53 & 6.35 & $1.39 \times 10^{-19}$ \\
\hline GYS2 & 27.66 & 34.52 & 5.97 & $1.40 \times 10^{-19}$ \\
\hline APOA5 & 27.42 & 34.33 & 3.79 & $1.71 \times 10^{-19}$ \\
\hline GLYAT & 27.35 & 34.27 & 5.77 & $1.82 \times 10^{-19}$ \\
\hline MASP2 & 27.18 & 34.14 & 4.55 & $2.10 \times 10^{-19}$ \\
\hline ADRA1A & 27.171 & 34.14 & 4.12 & $2.11 \times 10^{-19}$ \\
\hline PRODH2 & 26.66 & 33.73 & 2.63 & $3.27 \times 10^{-19}$ \\
\hline ABCB11 & 26.30 & 33.44 & 5.02 & $4.47 \times 10^{-19}$ \\
\hline APOM & 26.16 & 33.33 & 4.22 & $5.07 \times 10^{-19}$ \\
\hline CYP8B1 & 26.05 & 33.23 & 4.87 & $5.61 \times 10^{-19}$ \\
\hline SLC27A5 & 25.97 & 33.17 & 4.41 & $6.01 \times 10^{-19}$ \\
\hline C3P1 & 25.88 & 33.10 & 4.70 & $6.47 \times 10^{-19}$ \\
\hline SULT2A1 & 25.27 & 32.58 & 6.02 & $1.12 \times 10^{-18}$ \\
\hline CCL16 & 25.24 & 32.56 & 4.50 & $1.15 \times 10^{-18}$ \\
\hline F13B & 25.07 & 32.42 & 5.12 & $1.34 \times 10^{-18}$ \\
\hline ARG1 & 24.97 & 32.32 & 5.72 & $1.48 \times 10^{-18}$ \\
\hline FETUB & 24.66 & 32.05 & 5.12 & $1.97 \times 10^{-18}$ \\
\hline SPP2 & 24.36 & 31.80 & 5.27 & $2.59 \times 10^{-18}$ \\
\hline CPS1 & 11.43 & 15.54 & 6.78 & $3.87 \times 10^{-11}$ \\
\hline
\end{tabular}

lncRNA, long non-coding RNA.

and non-tumorous tissues using bioinformatics and the results are presented in Fig. 1A. The genes and lncRNAs exhibiting the greatest significant differences in expression between ICC and non-tumorous tissues were screened (Table I). The lncRNA CPS1-IT1 and its host gene CPS1 were observed to be co-expressed in ICC tissue $(\mathrm{P}<0.001$; Table I).

Expression of CPS1 mRNA and CPS1-IT1 is upregulated in clinical tissue specimens. The expression of CPS1 mRNA and CPS1-IT1 in ICC and non-tumorous tissues was measured using RT-qPCR, normalized to GAPDH mRNA and $\mathrm{u} 6$, respectively. The expression levels are presented as $\Delta \mathrm{Ct}$ values. A total of $26(83.87 \%)$ of the 31 ICC samples exhibited CPS1 mRNA expression $>1.00$, and the CPS1-IT1 relative expression was $>1$ in all 31 (100\%) of the cancer tissue samples (Fig. 1B). The P-value of $\Delta \mathrm{Ct}$ between cancer tissues $(8.39 \pm 3.15)$ and non-tumorous tissues $(9.82 \pm 3.78)$ was 0.09 (Fig. 1C). The $\Delta \mathrm{Ct}$ values of CPS1-IT1 in cancer tissues $(8.55 \pm 1.38)$ were significantly reduced compared with non-tumorous tissue $(11.10 \pm 0.47)(\mathrm{P}<0.001$; Fig. 1D). In addition, the relative expression levels (2- $2^{-\Delta \mathrm{C}}$; fold change) of CPS1 and CPS1-IT1 were significantly increased compared with non-tumorous tissue

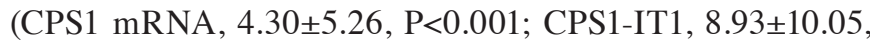
$\mathrm{P}<0.001)$.

CPS1 protein is upregulated in ICC specimens. Four pairs of cancer and non-tumorous tissues were randomly selected from the above 31 pairs of ICC specimens to measure the expression of CPS1 protein using western blotting. The patient ID numbers were 11, 15, 22 and 28. The CPS1 protein expression levels were greater in cancer tissues than in non-tumorous tissues in the first three cases, and the grey levels were similar (Fig. 2A). This result is in agreement with the above-mentioned RT-qPCR result.

CPS1 mRNA and CPS1-IT1 are co-expressed in ICC cells. The expression levels of CPS1 mRNA and CPS1-IT1 were measured in L-02 normal liver cells, ICC-9810 cells and HepG2, MHCC-97L, Huh-7 and Bel-7402 hepatocellular carcinoma cell lines using RT-qPCR. The expression levels were reported as $\Delta \mathrm{Ct}$ values. The $\Delta \mathrm{Ct}$ values of CPS1 mRNA and CPS1-IT1 in ICC-9810 cells were significantly reduced compared with the expression in $\mathrm{L}-02$ cells $(\mathrm{P}=0.05$; Fig. 2B and C). In addition, similar results were observed in 
Table II. Survival analysis with different fold changes of CPS1 and CPS1-IT1.

\begin{tabular}{|c|c|c|c|c|c|c|}
\hline \multirow[b]{2}{*}{ Fold change } & \multicolumn{3}{|c|}{ CSP1 } & \multicolumn{3}{|c|}{ CSP1-IT1 } \\
\hline & Up/down & $\begin{array}{c}\text { Disease-free survival } \\
\text { P-value }\end{array}$ & $\begin{array}{c}\text { Overall survival } \\
\text { P-value }\end{array}$ & Up/down & $\begin{array}{c}\text { Disease-free survival } \\
\text { P-value }\end{array}$ & $\begin{array}{c}\text { Overall survival } \\
\text { P-value }\end{array}$ \\
\hline 1 & $26 / 5$ & 0.531 & 0.574 & $31 / 0$ & & \\
\hline 2 & $21 / 10$ & 0.068 & 0.290 & $24 / 7$ & 0.616 & 0.810 \\
\hline 3 & $18 / 13$ & 0.211 & 0.239 & $23 / 8$ & 0.179 & 0.432 \\
\hline 4 & $10 / 21$ & 0.034 & 0.441 & $22 / 9$ & 0.026 & 0.192 \\
\hline 5 & $6 / 25$ & 0.008 & 0.032 & $19 / 12$ & 0.045 & 0.435 \\
\hline 6 & $4 / 27$ & 0.047 & 0.174 & $19 / 12$ & 0.045 & 0.435 \\
\hline 7 & $3 / 28$ & 0.121 & 0.454 & $18 / 13$ & 0.049 & 0.532 \\
\hline 8 & $3 / 28$ & 0.121 & 0.454 & $16 / 15$ & 0.004 & 0.338 \\
\hline 9 & $3 / 28$ & 0.121 & 0.454 & $10 / 21$ & 0.002 & 0.309 \\
\hline 10 & $3 / 28$ & 0.121 & 0.454 & $8 / 23$ & 0.006 & 0.106 \\
\hline 11 & $3 / 28$ & 0.121 & 0.454 & $5 / 26$ & 0.017 & 0.074 \\
\hline 12 & $3 / 28$ & 0.121 & 0.454 & $5 / 26$ & 0.017 & 0.074 \\
\hline
\end{tabular}

CPS1, carbamoyl-phosphate synthase 1; CPS1-IT1, CPS1 intronic transcript 1.

A

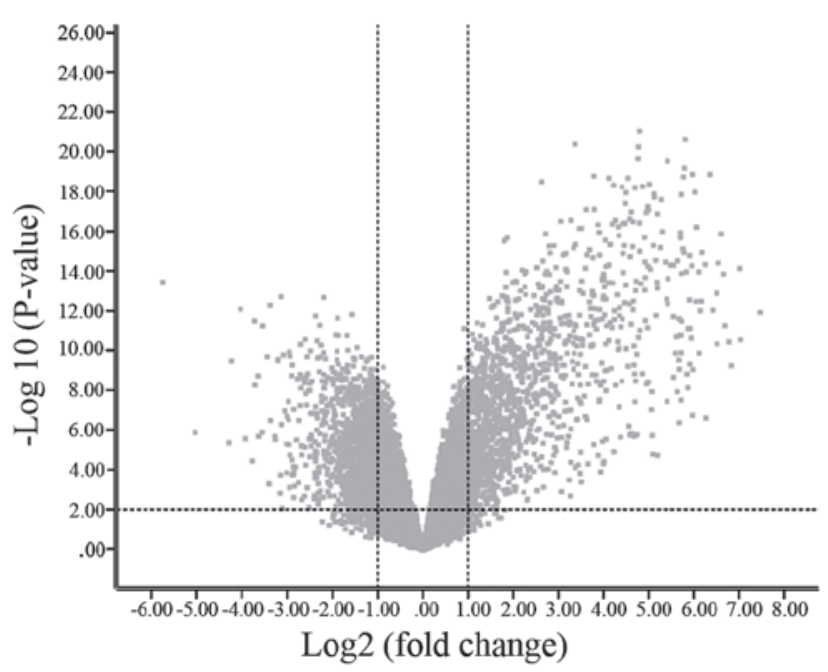

C

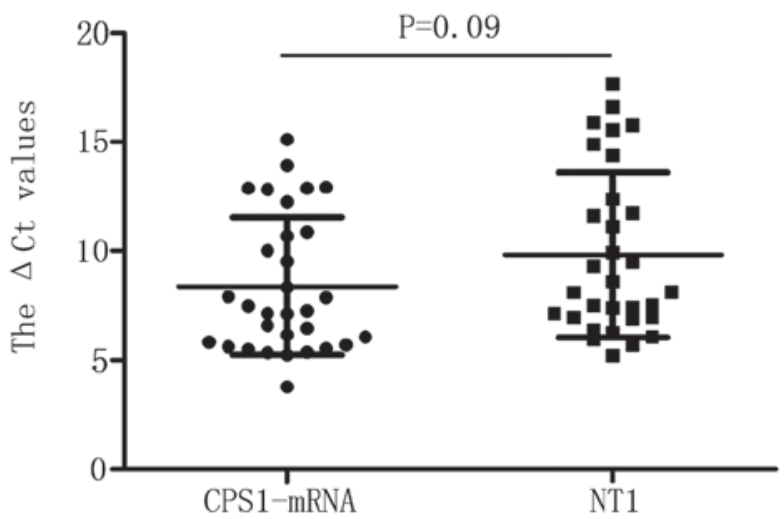

B

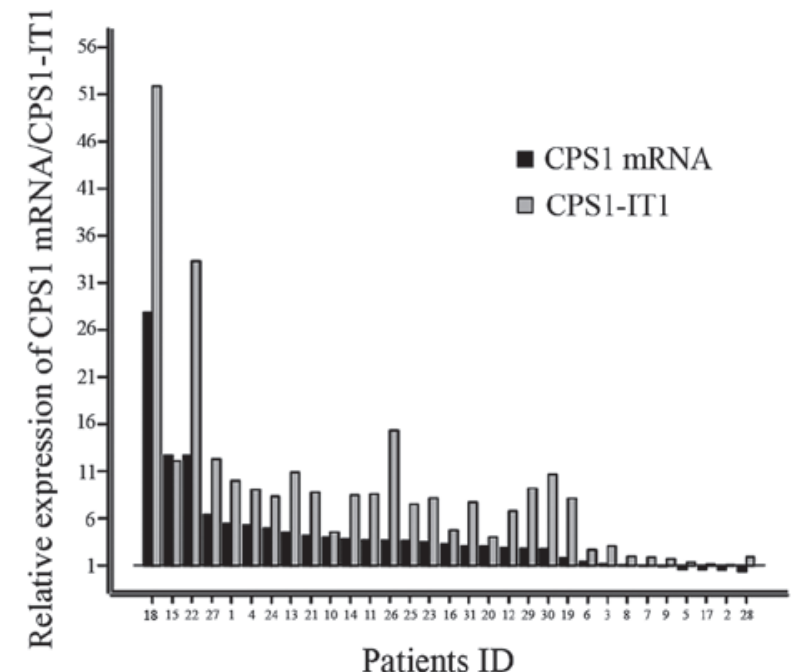

D

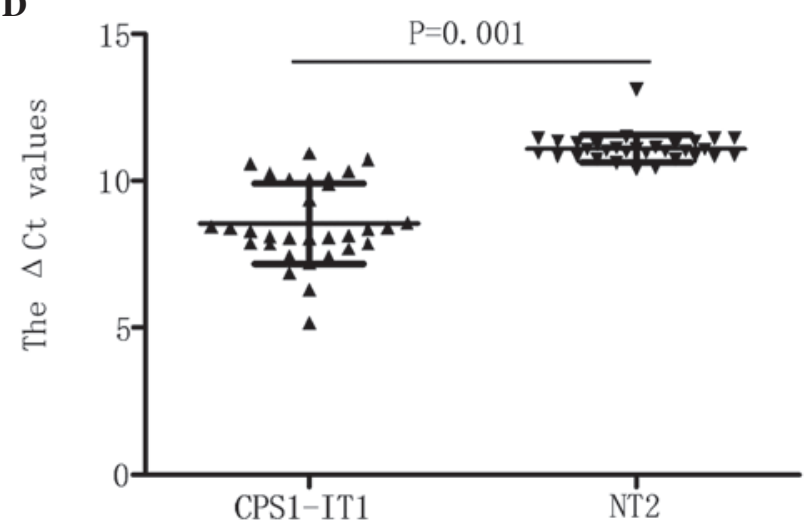

Figure 1. CPS1 and CPS1-IT1 were upregulated in ICC specimens. (A) The gene and long non-coding RNA expression fold changes and P-values between ICC tissues and adjacent non-tumorous tissues. The points in the upper left and upper right areas of the 6-lattice region divided by the three dotted lines represent notable factors with respect to fold change and P-value. (B) The relative expression (fold change) of CPS1 mRNA and matched CPS1-IT1 expression level in cancer tissues. (C) CPS1 and (D) CPS1-IT1 mRNA expression in tumorous and non-tumorous tissue of patients with ICC using reverse transcription-quantitative polymerase chain reaction. The expression level is presented as the $\Delta \mathrm{Ct}$ values ( $\mathrm{n}=31$ ). CPS1, carbamoyl-phosphate synthase 1; CPS1-IT1, CPS1 intronic transcript 1; ICC, intrahepatic cholangiocarcinoma; NT, non-tumorous. 
A

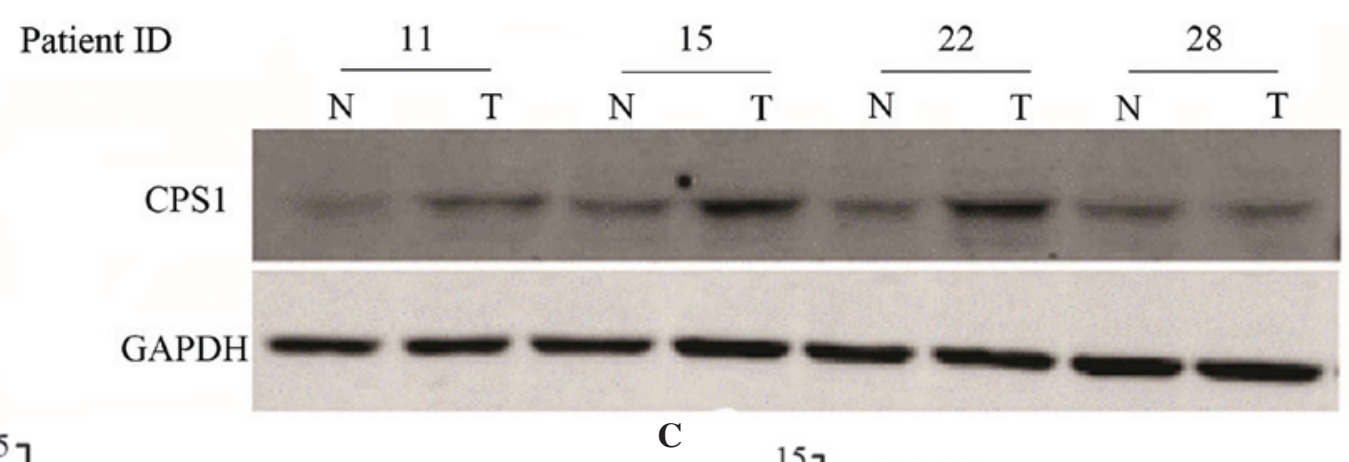

B
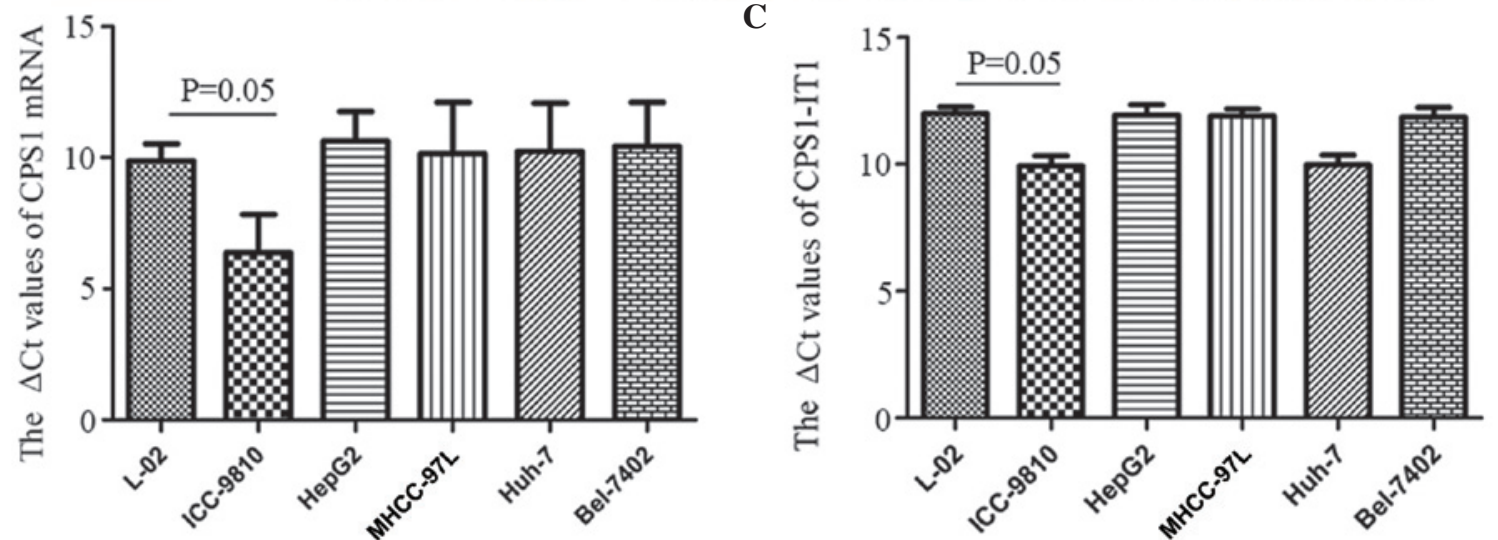

D
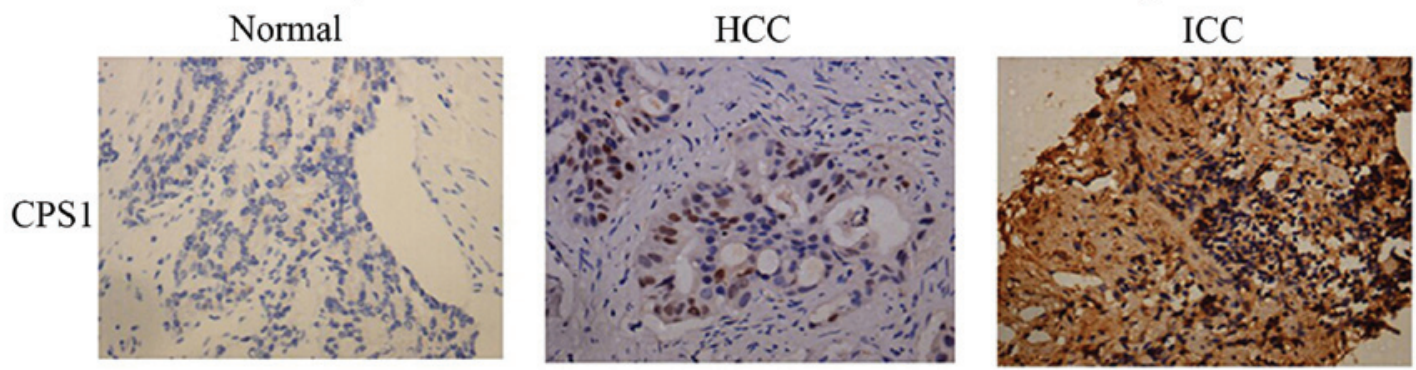

Figure 2. CPS1 mRNA and CPS1-IT1 expression in ICC specimens and cell lines by western blotting, RT-qPCR and immunohistochemistry. (A) The CPS1 protein levels in ICC specimens of patients 11, 15, 22 and 28. The expression of (B) CPS1 mRNA and (C) CPS1-IT1 in L-02 normal liver cells, ICC-9810 cells and HepG2, MHCC-97L, Huh-7 and Bel-7402 hepatocellular carcinoma cell lines using RT-qPCR. The $\triangle \mathrm{Ct}$ values of CPS1 mRNA and CPS1-IT1 in the ICC-9810 cells were significantly reduced compared with the expression in the L-02 cells ( $\mathrm{P}=0.05)$. (D) Normal human liver tissue, HCC tissue and ICC tissue stained with anti-CPS1 antibodies. The ICC tumor tissues exhibited greater CPS1 immunoreactivity compared with normal liver tissue and HCC tumor tissue. Magnification, x20. CPS1, carbamoyl-phosphate synthase 1; CPS1-IT1, CPS1 intronic transcript 1; ICC, intrahepatic cholangiocarcinoma; RT-qPCR, reverse transcription-quantitative polymerase chain reaction; HCC, human hepatocellular carcinoma; N, adjacent non-tumor tissue; T, tumor tissue.

the Huh-7 cells, as compared with the L-02 cells. However, no significant differences were observed in the expression levels of CPS1 mRNA and CPS1-IT1 in L-02 cells compared with the remaining hepatocellular carcinoma cell lines investigated (Fig. 2B and C).

CPS1 protein expression is upregulated in ICC tissues as measured by immunohistochemical staining. Immunohistochemical results indicated that CPS1 protein was highly expressed in the ICC tissue specimens. The ICC tissues exhibited increased expression levels of CPS1 compared with normal liver tissue and hepatocellular carcinoma tissue (Fig. 2D). The immunohistochemical staining results demonstrated that CPS1 protein expression was upregulated in ICC tissue samples (Fig. 2D).

Expression of CPS1 mRNA and CPS1-IT1 in ICC cell lines subject to RNAi. CPS1 and CPS1-IT1 knockdown ICC cell lines were generated using RNAi, in addition to a negative control cell line. The expression of CPS1 mRNA and CPS1-IT1 in each group was measured using RT-qPCR. The results are presented in Fig. 3A and indicate that the expression levels of CPS1 and CPS1-IT1 were reduced by RNAi mediated knock down in the ICC-9810 cells.

CPS1 and CPS1-IT1 knockdown inhibits ICC cell proliferation and accelerated cell apoptosis. The CCK8 determination of cell proliferation is presented in Fig. 3B. The OD 450 values of the scramble group were significantly different compared with the siCPS1, siCPS1-IT1 and siCPS1 + siCPS1-IT1 groups on days 3 and 4 of incubation with siRNA $\left(\mathrm{P} 3=1.16 \times 10^{-5} ; \mathrm{P} 4=8.04 \times 10^{-6}\right)$. In addition, significant differences in the OD 450 values were observed between the siCPS1 group and the siCPS1-IT1 group on day $3(\mathrm{P}=0.022)$. There were no significant differences in the OD 450 values between the remaining groups. These data demonstrate that knockdown of CPS1 or CPS1-IT1 inhibits the proliferation of ICC cells.

The level of apoptosis was measured using flow cytometry following 4 days in culture with siRNA. The apoptotic rates of 


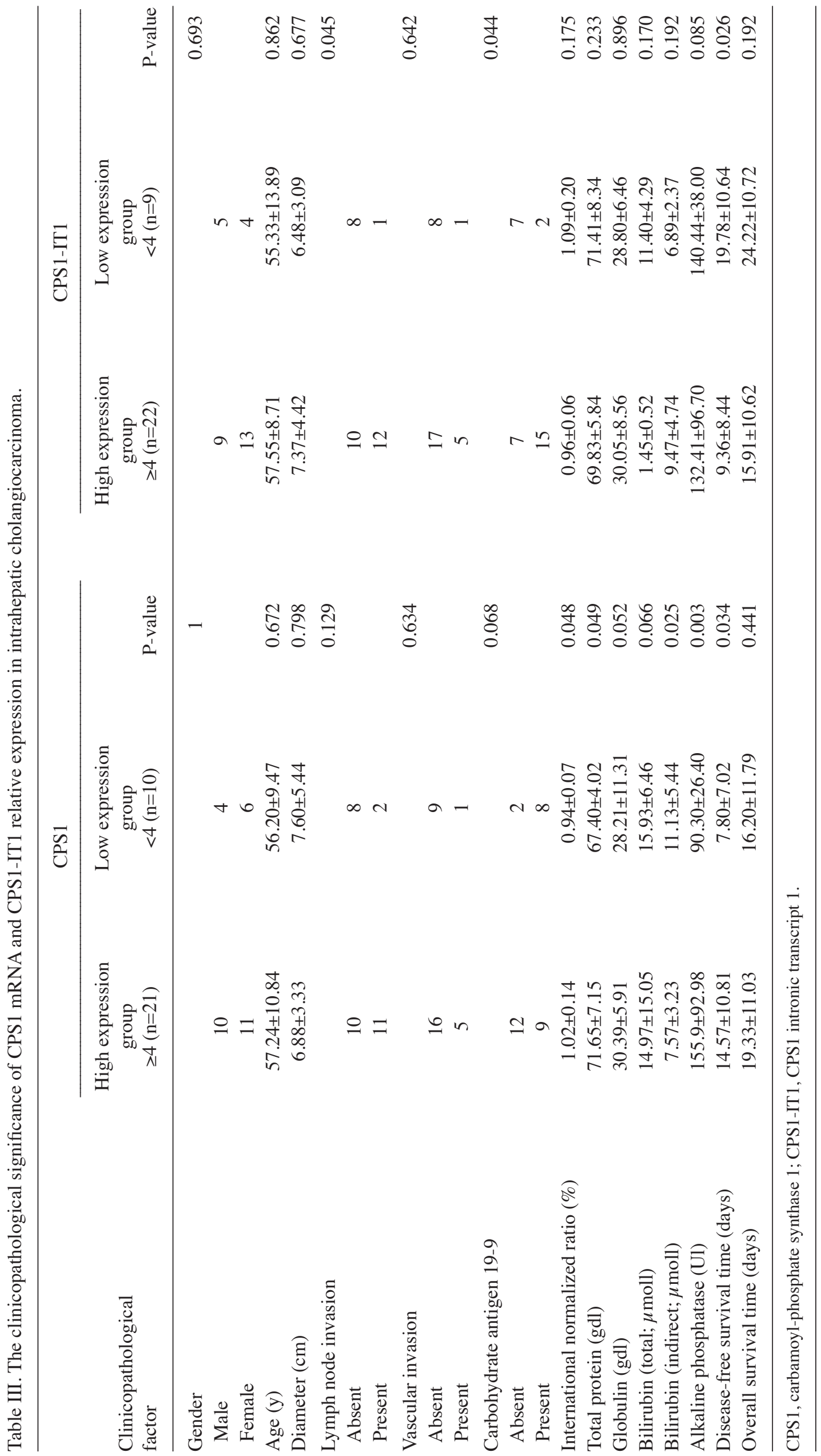


A

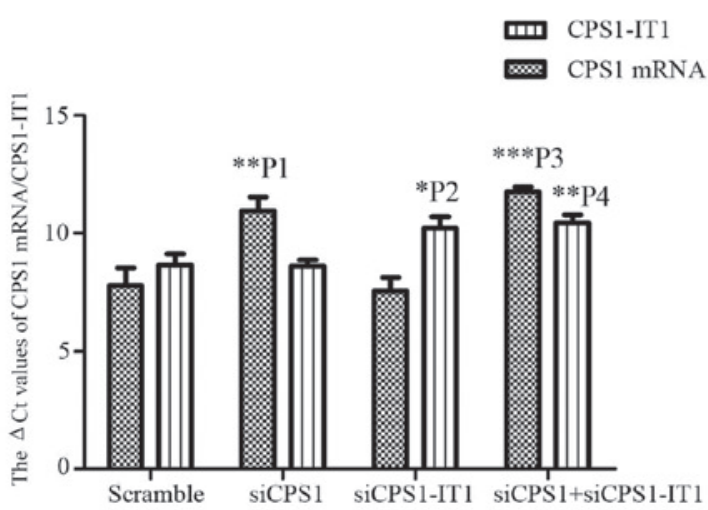

C

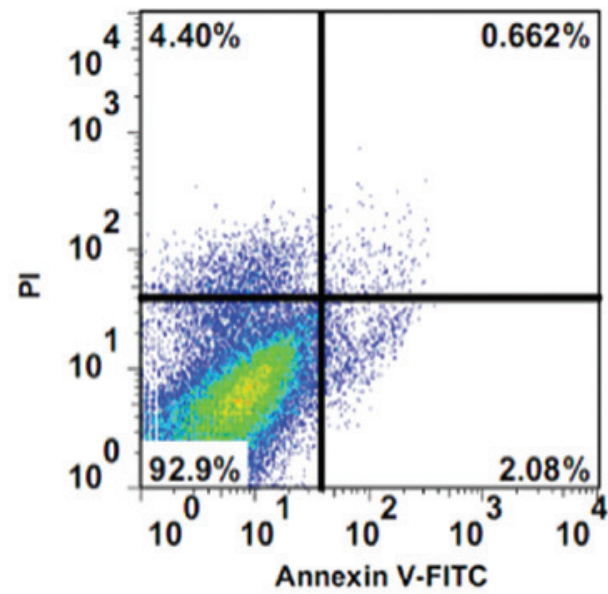

$\mathbf{E}$

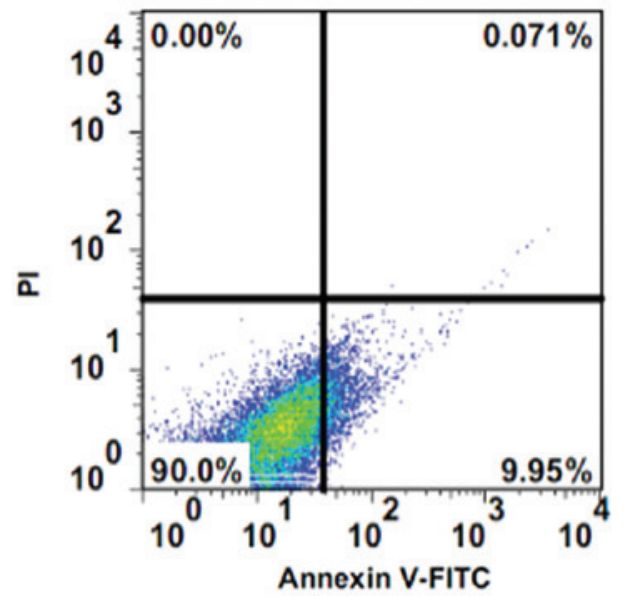

B

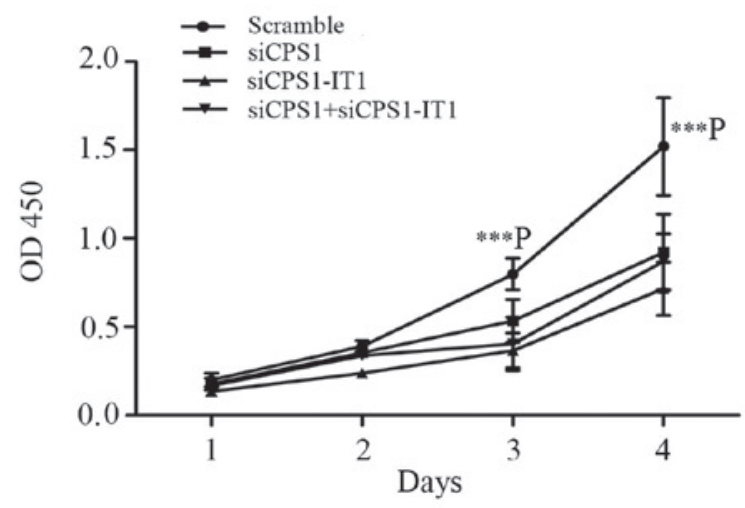

D

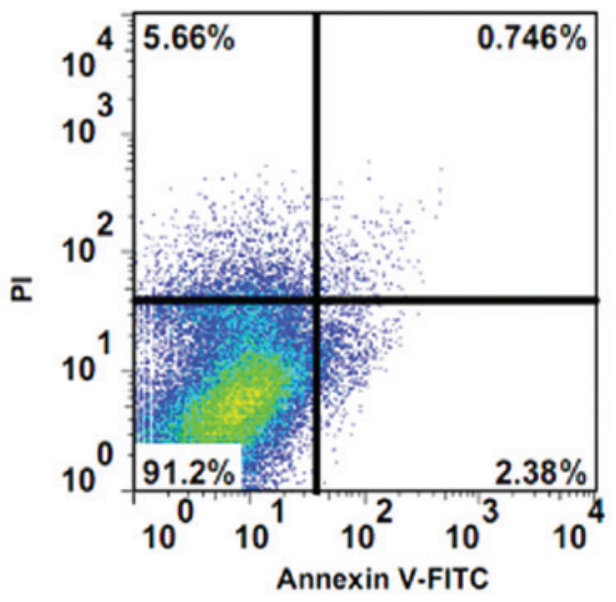

$\mathbf{F}$

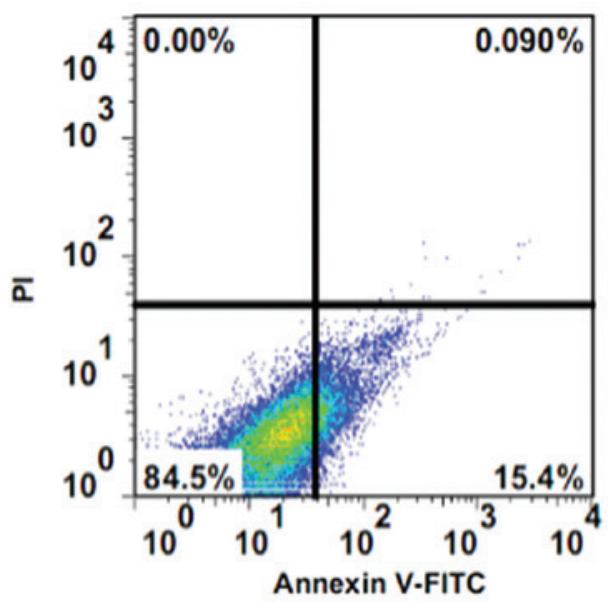

Figure 3. Cell proliferation and apoptosis in the different groups. (A) The expression of CPS1 mRNA and CPS1-IT1 in the cell groups. P1=0.005; P2=0.018; $\mathrm{P} 3=0.001 ; \mathrm{P} 4=0.006$. (B) Cell Counting Kit- 8 determination of cell proliferation. The OD 450 values of the scramble group were significantly different from the three knockdown groups on days 3 and $4 .{ }^{* * *} \mathrm{P}<0.001$. The rate of apoptosis in the (C) scramble, (D) siCPS1, (E) siCPS1-IT1 and (F) siCPS1 + siCPS1-IT1 groups was measured by annexin V-FITC and PI staining. Apoptotic cells were calculated as the upper right + lower right quadrants. The values are: Scramble, 2.742\%; siCPS1, 3.126\%; siCPS1-IT1, 10.021\%; and siCPS1 + siCPS1-IT1, 15.49\%. CPS1, carbamoyl-phosphate synthase 1; CPS1-IT1, CPS1 intronic transcript 1; si, short interfering; OD, optical density; FITC, fluorescein isothiocyanate; PI, propidium iodide.

the scramble, siCPS1, siCPS1-IT1 and siCPS1 + siCPS1-IT1 groups were $2.742,3.126,10.021$ and $15.49 \%$, respectively (Fig. 3C-3F).

The immunofluorescence results are presented in Fig. 4. Cell proliferation was detected using Ki67. The intensity of Ki67 staining was reduced in the ICC cell lines in the siCPS1 and/or siCPS1-IT1 groups, as compared with the negative control siRNA group. These data suggest that CPS1 and/or CPS1-IT1 knockdown inhibits ICC cell proliferation.
Increased CPS1 $m R N A$ and CPS1-IT1 expression affects the prognosis of patents with ICC. The association between the prognosis of patients with ICC and the relative expression of CPS1 mRNA and CPS1-IT1 was investigated (Table II). In samples in which the relative expression of CPS1 mRNA in tumor tissues increased 4-fold and 5-fold compared with non-tumorous tissues, a significant effect on the disease-free survival and overall survival of patients with ICC was observed (P4-free $=0.034$, P5-sur=0.032; Fig. 5A and B). The relative 


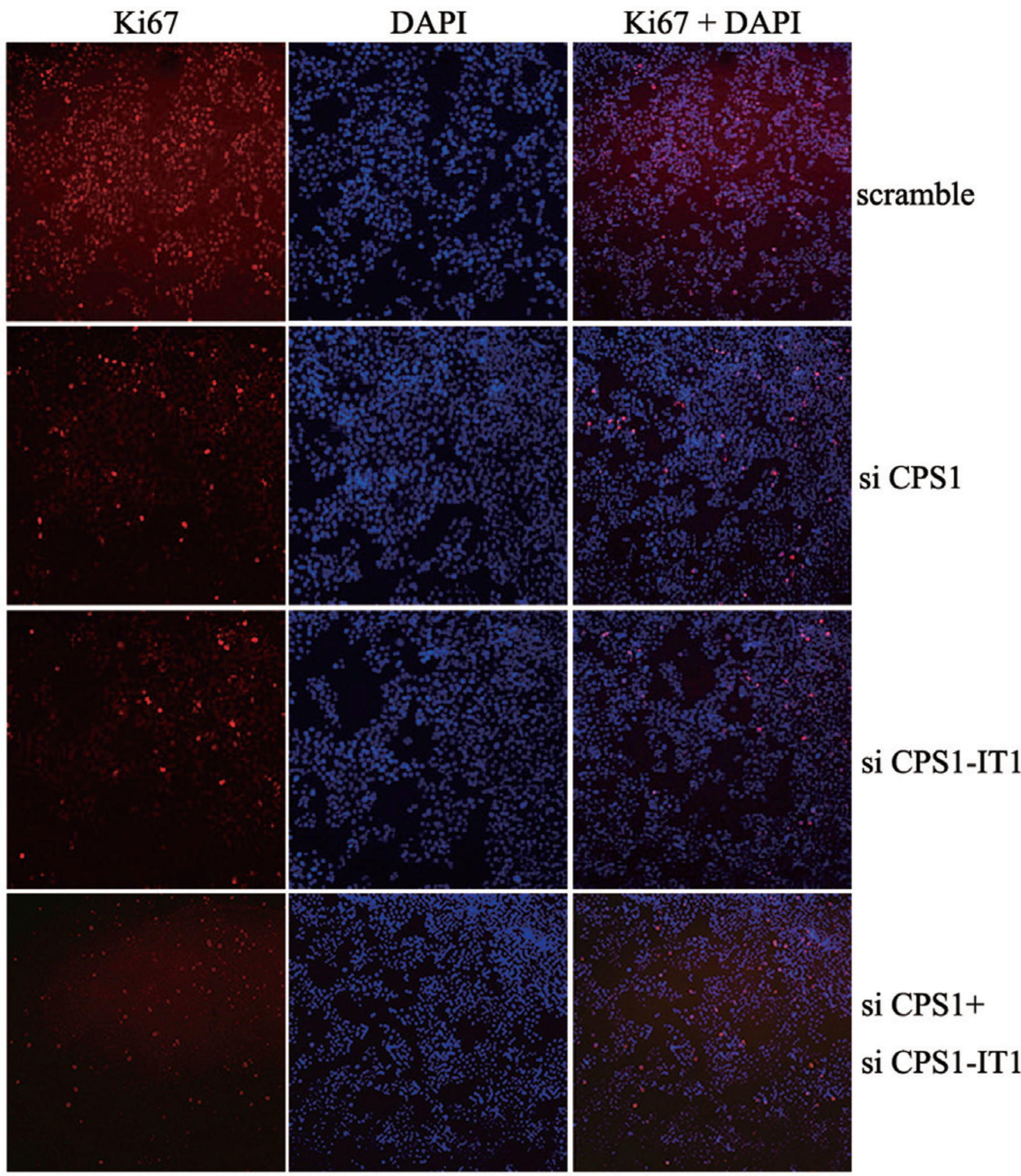

Figure 4. Immunofluorescence with Ki67 and DAPI in different ICC cell groups. Top line, scramble ICC cell group; second line, CPS1 knockout ICC cell group; third line, CPS1-IT1 knockout ICC cell group; and the bottom line, CPS1 + CPS1-IT1 knockout ICC cell group. The left column was stained with Ki67 to indicate proliferation; the middle column was stained with DAPI to indicate the nuclei; and the right column contains the merged images. The intensity of Ki67 staining was reduced in ICC cells in which CPS1, CPS1-IT1 or both were knocked down compared with the scramble group. DAPI, 4',6-diamidino-2-phenylindole; ICC, intrahepatic cholangiocarcinoma; CPS1, carbamoyl-phosphate synthase 1; CPS1-IT1, CPS1 intronic transcript 1.

expression of CPS1-IT1 in tumor tissue appeared to affect the disease-free survival when the levels increased greater than 4-fold, however the overall survival rates were not significantly altered (P4-free=0.026, P4-sur=0.192; Fig. 5C and D).
Clinicopathological significance of CPS1 mRNA and CPS1-IT1 relative expression in ICC. The clinicopathological features analyzed with respect to the relative expression status of CPS1 mRNA and CPS1-IT1 are presented in Table III. The 
A

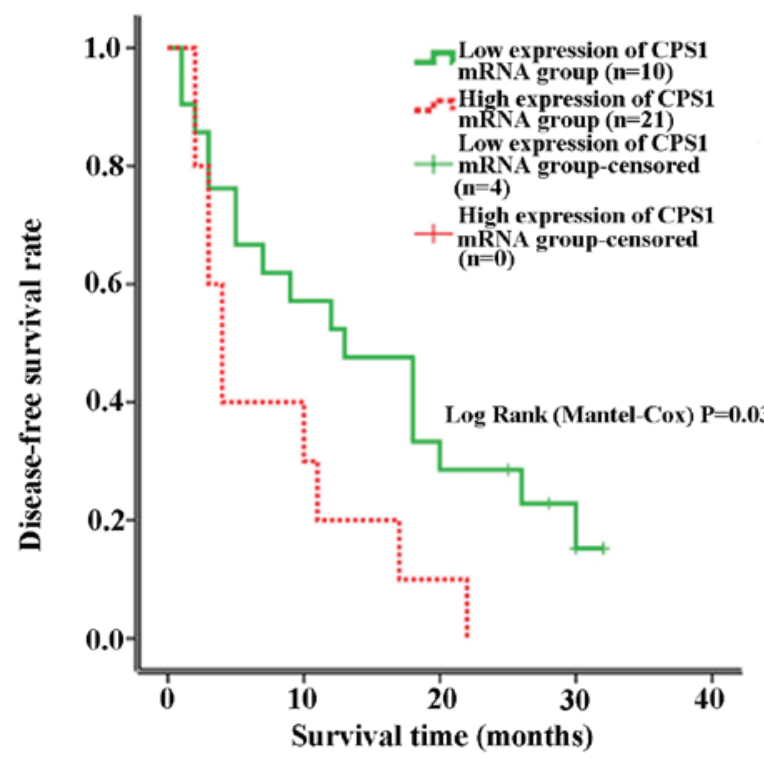

C

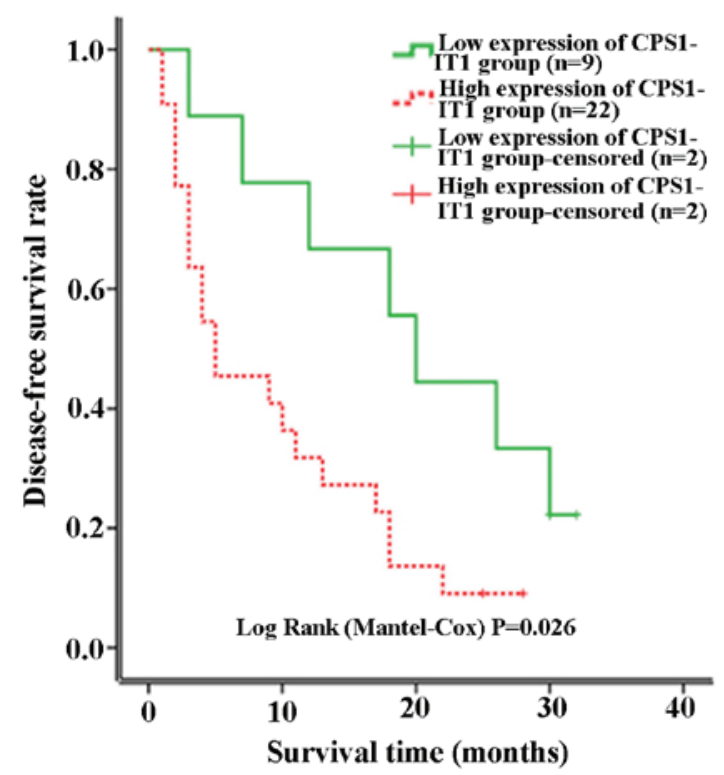

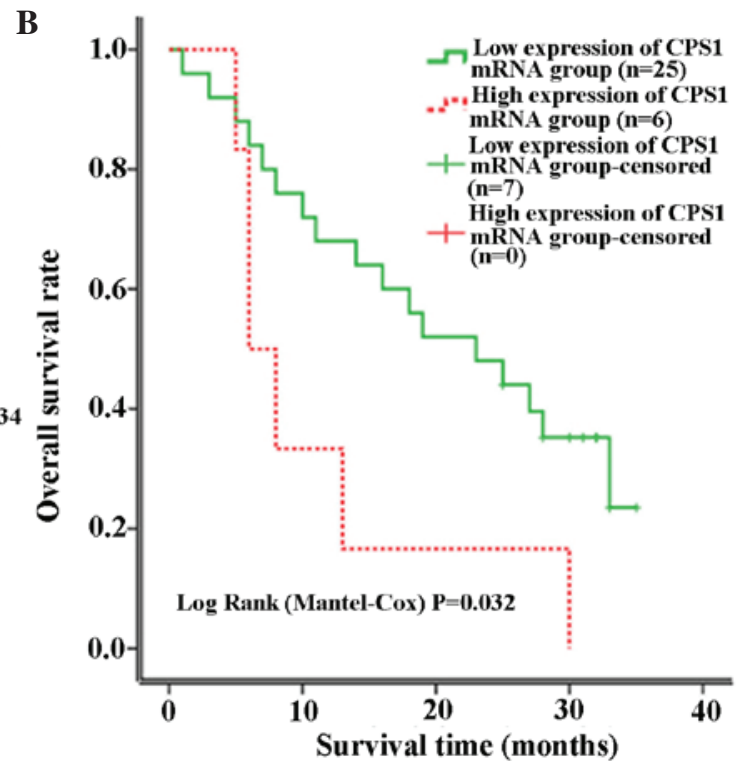

D

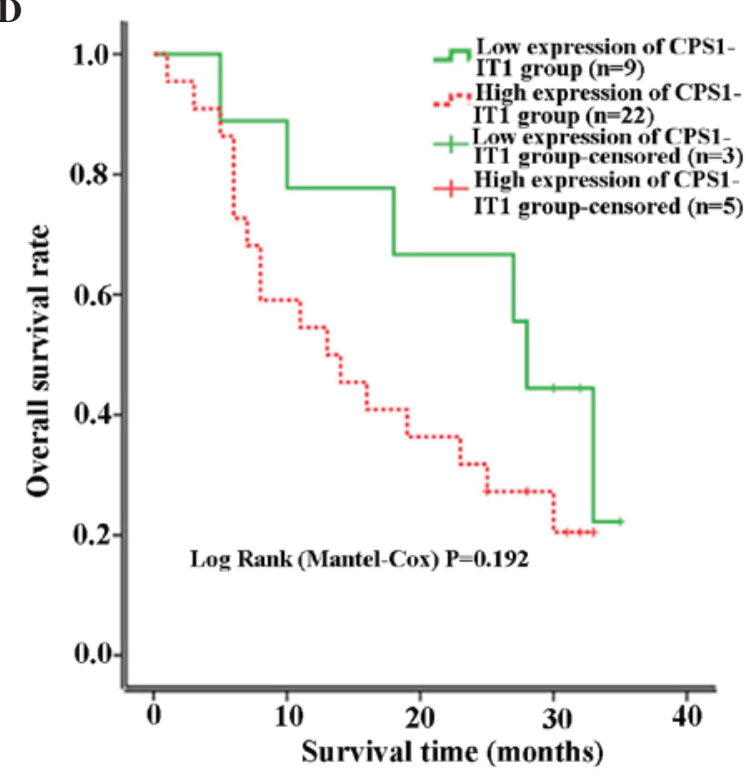

Figure 5. Association of CPS1 and CPS1-IT1 expression with prognosis. (A) CPS1 mRNA disease-free survival rate curves: High expression group (n=10), CPS1 mRNAGAPDH $\geq 4$; low expression group (n=21), CPS1 mRNAGAPDH <4 (P4-free=0.034). (B) CPS1 mRNA overall survival rate curves: High expression group ( $n=6$ ), CPS1 mRNAGAPDH $\geq 5$; low expression group ( $\mathrm{n}=25)$, CPS1 mRNAGAPDH $<5$ (P5-sur=0.032). (C) CPS1-IT1 disease-free survival rate curves: High expression group ( $\mathrm{n}=22$ ), CPS1-IT1u6 $\geq 4$; low expression group ( $\mathrm{n=9}$ ), CPS1-IT1u6 <4 (P4-free=0.026). (D) CPS1-IT1 overall survival rate curves: High expression group ( $\mathrm{n}=22$ ), CPS1-IT1u6 $\geq 4$; low expression group (n=9), CPS1-IT1u6 <4 (P4-sur=0.192). CPS1, carbamoyl-phosphate synthase 1; CPS1-IT1, CPS1 intronic transcript 1; GAPDH, glyceraldehyde 3-phosphate dehydrogenase; P4-free, the P-value of the disease-free survival rate associated with a 4-fold change; P5-sur, the P-value of the overall survival rate associated with a 5-fold change; P4-sur, the P-value of the overall survival rate associated with a 4-fold change.

comparisons between the high CPS1 expression group and the low expression group indicated significant differences in international normalized ratio (INR) $(\mathrm{P}=0.048)$, total protein $(\mathrm{P}=0.049)$, indirect bilirubin $(\mathrm{P}=0.025)$, alkaline phosphatase (ALP; $\mathrm{P}=0.003)$ and disease-free survival $(\mathrm{P}=0.034)$; furthermore, there were differential trends in carbohydrate antigen 19-9 (CA19-9; $\mathrm{P}=0.068)$, globulin $(\mathrm{P}=0.052)$, and total bilirubin $(\mathrm{P}=0.066)$. The comparisons between the high CPS1-IT1 expression group and the low expression group revealed significant differences in lymphatic invasion $(\mathrm{P}=0.045), \mathrm{CA} 19-9$ $(\mathrm{P}=0.044)$ and disease-free survival $(\mathrm{P}=0.026)$; there were also differential trends in ALP $(\mathrm{P}=0.085)$. However, no significant differences were observed with respect to age, gender, tumor size or vascular invasion with either CPS1 mRNA or CPS1-IT1. These data suggest that CPS1 and CPS1-IT1 are associated with poor liver function and increased lymph node invasion in patients exhibiting a $\geq 4$-fold increase in expression in cancer tissues.

\section{Discussion}

Studies on the pathogenesis and prognosis of ICC have gained interest worldwide. Approximately $18 \%$ of protein-coding genes have been demonstrated to transcribe IncRNAs, and 
lncRNA expression is associated with cancer (35). However, the expression and role of lncRNAs in ICC remain to be fully elucidated.

Converting toxic ammonium into less toxic urea is one of the major functions of the liver and is accomplished via the urea cycle $(36,37)$. CPS1 protein, which is expressed by the CPS1 gene, is the first key enzyme in this process and serves important roles in the urea cycle (24). The lncRNA CPS1-IT1 is transcribed by the CPS1 gene from 211,482,295-211,484,600 base pairs and encodes an RNA molecule 2,306 bases in length (http://www.genecards. org/cgi-bin/carddisp.pl?gene $=$ CPS1-IT1\&keywords $=$ CPS 1-IT1).

The level of CPS1 expression varies in numerous types of human cancer tissue, and its clinical significance remains to be fully elucidated $(38,39)$. Approximately $70.5 \%$ of cases of gastric carcinoma have been reported to be CPS1-positive, and CPS1 may be used as a marker for diagnosis (38). In hepatocellular carcinoma tissue, the expression of CPS1 is reduced due to DNA methylation (39). The present study in ICC demonstrated for the first time, to the best of our knowledge, that CPS1 and CPS1-IT1 are simultaneously overexpressed in cancer tissues relative to non-tumorous tissues, and that high expression of CPS1 and CPS1-IT1 correlates with poor prognosis.

In the current study the expression of CPS1 protein in ICC tissues was assessed using western blotting and immunohistochemical staining. Furthermore, the differential expression of CPS1 mRNA and CPS1-IT1 was measured in a normal cell line, ICC cell line and hepatocellular carcinoma cell lines by RT-qPCR (Fig. 2). Additionally, immunofluorescence, flow cytometry analysis and a CCK8 in vitro proliferation assay demonstrated that CPS1 and CPS1-IT1 promote proliferation and inhibit apoptosis in ICC cells (Figs. 3 and 4). Notably, the expression of CPS1 and CPS1-IT1 are correlated; CPS1-IT1 expression increased with increasing CPS1 expression (Fig 1B). These data suggest that CPS1 and CPS1-IT1 may affect ICC together. However, the mechanisms of interaction among these two products remain unclear and require further study.

The effect of CPS1 and CPS1-IT1 expression on the prognosis of patients with ICC was analyzed. However, there are no uniform standards defining increased and reduced expression levels. Therefore, a preliminary analysis was conducted to determine this standard (Table II). These results indicated that increased expression of CPS1 or CPS1-IT1 (4 to 5-fold change) impacted on the survival rates of patients with ICC (Table II). CPS1 and CPS1-IT1 levels affected the disease-free survival rate when expression levels were elevated greater than 4-fold. It is possible that the overall survival rate is affected by numerous factors, such as variance in patient motivation to receive continued treatment.

Notably, the clinicopathological features analysis indicated that increased expression of CPS1 correlated with greater INR, total protein and ALP levels, and a reduced indirect bilirubin level. In addition, with increasing CPS1-TI1 expression, increased lymphatic invasion and CA19-9 positivity was observed (Table III). These correlations suggest that the expression of CPS1 and CPS1-IT1 may be associated with poor liver function and prognosis. However, the present study had a small sample size (31 specimens). The impact of CPS1 expression on
CA19-9, globulin and total bilirubin levels, and of CPS1-IT1 expression on ALP levels, exhibited a non-significant trend (Table III). Further studies with larger samples are required to confirm the significance of these associations.

Currently, ICC is difficult to treat for numerous reasons. The clinical presentation of ICC is non-specific and insufficient to establish a diagnosis. Patients with early stage disease are often asymptomatic, and those receiving treatment will have entered the advanced stages, thus may no longer be eligible for surgery (8). At present, CA19-9 is the primary tumor marker used to diagnose ICC and may be used preoperatively to assess tumor prognosis (40). However, the sensitivity and specificity of CA19-9 for ICC is $62 \%$ and $63 \%$, respectively (41). Furthermore, patients with unresectable ICC typically have significantly increased CA19-9 levels compared with patients with resectable ICC (42). Previous studies have reported that miRNA and non-coding RNA may be used to diagnose ICC alone or in combination (43-45). The current study demonstrates that with increasing expression of CPS1-IT1, the CA19-9 positive rate is greater $(\mathrm{P}=0.044)$, indicating that CPS1-IT1 may be a potential biomarker for ICC.

In conclusion, the current study demonstrated that the expression levels of CPS1 and CPS1-IT1 were increased in ICC tissues and cell lines. Together, CPS1 and CPS1-IT1 promoted ICC cellular proliferation. The overexpression of CPS1 was associated with poor liver function and poorer prognosis in patients with ICC. CPS1 and CPS1-IT1 may represent potential biomarkers and prognosis indicators for patients with ICC. Further basic and clinical studies with larger sample sizes that focus on the underlying mechanisms should be performed.

\section{Acknowledgements}

The authors would like to thank Professor Michael G. Sarrh at the Mayo Clinic (Rochester, MN, USA) for his contribution to this manuscript, and for his help and guidance with the experimental techniques. The current study was supported by the Shanghai Natural Science Foundation (grant no. 14ZR1409300).

\section{References}

1. Fan B, Malato Y, Calvisi DF, Naqvi S, Razumilava N, Ribback S, Gores GJ, Dombrowski F, Evert M, Chen X and Willenbring H: Cholangiocarcinomas can originate from hepatocytes in mice. J Clin Invest 122: 2911-2915, 2012.

2. Sekiya S and Suzuki A: Intrahepatic cholangiocarcinoma can arise from Notch-mediated conversion of hepatocytes. J Clin Invest 122: 3914-3918, 2012.

3. Khan SA, Toledano MB and Taylor-Robinson SD: Epidemiology, risk factors, and pathogenesis of cholangiocarcinoma. HPB Oxf 10: 77-82, 2008.

4. Shaib Y and El-Serag HB: The epidemiology of cholangiocarcinoma. Semin Liver Dis 24: 115-125, 2004.

5. Shaib YH, Davila JA, McGlynn K and El-Serag HB: Rising incidence of intrahepatic cholangiocarcinoma in the United States: A true increase? J Hepatol 40: 472-477, 2004.

6. Shimoda M and Kubota K: Multi-disciplinary treatment for cholangiocellular carcinoma. World J Gastroenterol 13: 1500-1504, 2007.

7. Bragazzi MC, Cardinale V, Carpino G, Venere R, Semeraro R, Gentile R, Gaudio E, Alvaro D: Cholangiocarcinoma: Epidemiology and risk factors. Transl Gastrointest Cancer 1: 21-32, 2012. 
8. Bridgewater J, Galle PR, Khan SA, Llovet JM, Park JW, Patel T, Pawlik TM and Gores GJ: Guidelines for the diagnosis and management of intrahepatic cholangiocarcinoma. J Hepatol 60: $1268-1289,2014$

9. Tan JC, Coburn NG, Baxter NN, Kiss A and Law CH: Surgical management of intrahepatic cholangiocarcinoma--a population-based study. Ann Surg Oncol 15: 600-608, 2008.

10. de Jong MC, Nathan H, Sotiropoulos GC, Paul A, Alexandrescu S, Marques H, Pulitano C, Barroso E, Clary BM, Aldrighetti L, et al: Intrahepatic cholangiocarcinoma: An international multi-institutional analysis of prognostic factors and lymph node assessment. J Clin Oncol 29: 3140-3145, 2011.

11. Endo I, Gonen M, Yopp AC, Dalal KM, Zhou Q, Klimstra D, D'Angelica M, DeMatteo RP, Fong Y, Schwartz L, et al: Intrahepatic cholangiocarcinoma: Rising frequency, improved survival, and determinants of outcome after resection. Ann Surg 248: 84-96, 2008.

12. Choi SB, Kim KS, Choi JY, Park SW, Choi JS, Lee WJ and Chung JB: The prognosis and survival outcome of intrahepatic cholangiocarcinoma following surgical resection: Association of lymph node metastasis and lymph node dissection with survival. Ann Surg Oncol 16: 3048-3056, 2009.

13. Shimada K, Sano T, Nara S, Esaki M, Sakamoto Y, Kosuge T and Ojima $\mathrm{H}$ : Therapeutic value of lymph node dissection during hepatectomy in patients with intrahepatic cholangiocellular carcinoma with negative lymph node involvement. Surgery 145 411-416, 2009

14. Sia D, Hoshida Y, Villanueva A, Roayaie S, Ferrer J, Tabak B, Peix J, Sole M, Tovar V, Alsinet C, et al: Integrative molecular analysis of intrahepatic cholangiocarcinoma reveals 2 classes that have different outcomes. Gastroenterology 144: 829-840, 2013.

15. Edge SB and Compton CC: The American Joint Committee on Cancer: the 7th edition of the AJCC cancer staging manual and the future of TNM. Ann Surg Oncol 17: 1471-1474, 2010.

16. Mercer TR, Dinger ME and Mattick JS: Long non-coding RNAs: Insights into functions. Nat Rev Genet 10: 155-159, 2009.

17. Wapinski $\mathrm{O}$ and Chang HY: Long noncoding RNAs and human disease. Trends Cell Biol 21: 354-361, 2011.

18. Klecka J, Holubec L, Pesta M, Topolcan O, Hora M, Eret V, Finek J, Chottova-Dvorakova M, Babjuk M, Novak K and Stolz J: Differential display code 3 (DD3PCA3) in prostate cancer diagnosis. Anticancer Res 30: 665-670, 2010

19. Shen M, Chen W, Yu K, Chen Z, Zhou W, Lin X, Weng Z, Li C, Wu X and Tao Z: The diagnostic value of PCA3 gene-based analysis of urine sediments after digital rectal examination for prostate cancer in a Chinese population. Exp Mol Pathol 90: 97-100, 2011.

20. Ji P, Diederichs S, Wang W, Böing S, Metzger R, Schneider PM Tidow N, Brandt B, Buerger H, Bulk E, et al: MALAT-1, a novel noncoding RNA, and thymosin beta4 predict metastasis and survival in early-stage non-small cell lung cancer. Oncogene 22 8031-8041, 2003

21. Lai MC, Yang Z, Zhou L, Zhu QQ, Xie HY, Zhang F, Wu LM, Chen LM and Zheng SS: Long non-coding RNA MALAT-1 overexpression predicts tumor recurrence of hepatocellular carcinoma after liver transplantation. Med Oncol 29: 1810-1816, 2012.

22. Chakravadhanula M, Ozols VV, Hampton CN, Zhou L, Catchpoole D and Bhardwaj RD: Expression of the HOX genes and HOTAIR in atypical teratoid rhabdoid tumors and other pediatric brain tumors. Cancer Genet 207: 425-428, 2014.

23. Park JY, Lee JE, Park JB, Yoo H, Lee SH and Kim JH: Roles of Long Non-Coding RNAs on Tumorigenesis and Glioma Development. Brain Tumor Res Treat 2: 1-6, 2014.

24. Mian A and Lee B: Urea-cycle disorders as a paradigm for inborn errors of hepatocyte metabolism. Trends Mol Med 8: 583-589, 2002.

25. Mei D, Song H, Wang K, Lou Y, Sun W, Liu Z, Ding X and Guo J: Up-regulation of SUMO1 pseudogene 3 (SUMO1P3) in gastric cancer and its clinical association. Med Oncol 30: 709, 2013.

26. Sun W, Wu Y, Yu X, Liu Y, Song H, Xia T, Xiao B and Guo J: Decreased expression of long noncoding RNA AC096655.1-002 in gastric cancer and its clinical significance. Tumour Biol 34: 2697-2701, 2013
27. Jiang Z, Guo J, Xiao B, Miao Y, Huang R, Li D and Zhang Y: Increased expression of miR-421 in human gastric carcinoma and its clinical association. J Gastroenterol 45: 17-23, 2010.

28. Wang Y, Hong Y, Li M, Long J, Zhao YP, Zhang JX, Li Q, You H, Tong WM, Jia JD and Huang J: Mutation inactivation of Nijmegen breakage syndrome gene (NBS1) in hepatocellular carcinoma and intrahepatic cholangiocarcinoma. PLoS One 8: e82426, 2013.

29. Yao C, Oh JH, Oh IG, Park CH and Chung JH: [6]-Shogaol inhibits melanogenesis in B16 mouse melanoma cells through activation of the ERK pathway. Acta Pharmacol Sin 34: 289-294, 2013

30. Zhang H, Zhou WC, Li X, Meng WB, Zhang L, Zhu XL, Zhu KX, Bai ZT, Yan J, Liu T, et al: 5-Azacytidine suppresses the proliferation of pancreatic cancer cells by inhibiting the Wnt $\beta$-catenin signaling pathway. Genet Mol Res 13: 5064-5072, 2014.

31. Oishi N, Kumar MR, Roessler S, Ji J, Forgues M, Budhu A, Zhao X, Andersen JB, Ye QH, Jia HL, et al: Transcriptomic profiling reveals hepatic stem-like gene signatures and interplay of miR-200c and epithelial-mesenchymal transition in intrahepatic cholangiocarcinoma. Hepatology 56: 1792-1803, 2012.

32. Bonnefont J, Laforge T, Plastre O, Beck B, Sorce S, Dehay C and Krause KH: Primate-specific RFPL1 gene controls cell-cycle progression through cyclin B1/Cdc2 degradation. Cell Death Differ 18: 293-303, 2011.

33. Irizarry RA, Hobbs B, Collin F, Beazer-Barclay YD, Antonellis KJ, Scherf U, et al: Exploration, normalization, and summaries of high density oligonucleotide array probe level data. Biostatistics 4: 249-264, 2003.

34. Zhang X, Sun S, Pu JK, et al: Long non-coding RNA expression profiles predict clinical phenotypes in glioma. Neurobiol Dis 48: 1-8, 2012.

35. Khachane AN and Harrison PM: Mining mammalian transcript data for functional long non-coding RNAs. PLoS One 5: e10316, 2010

36. Morris SM Jr: Regulation of enzymes of urea and arginine synthesis. Annu Rev Nutr 12: 81-101, 1992.

37. Schofield JP: Molecular studies on an ancient gene encoding for carbamoyl-phosphate synthetase. Clin Sci (Lond) 84: 119-128, 1993.

38. Liu TH, Li DC, Gu CF and Ye SF: Carbamyl phosphate synthetase I. A novel marker for gastric carcinoma. Chin Med J (Engl) 102: 630-638, 1989.

39. Liu H, Dong H, Robertson K and Liu C: DNA methylation suppresses expression of the urea cycle enzyme carbamoyl phosphate synthetase 1 (CPS1) in human hepatocellular carcinoma. Am J Pathol 178: 652-661, 2011.

40. Tamandl D, Herberger B, Gruenberger B, Puhalla H, Klinger M and Gruenberger T: Influence of hepatic resection margin on recurrence and survival in intrahepatic cholangiocarcinoma. Ann Surg Oncol 15: 2787-2794, 2008.

41. Uenishi T, Yamazaki O, Tanaka H, Takemura S, Yamamoto T, Tanaka S, Nishiguchi S and Kubo S: Serum cytokeratin 19 fragment (CYFRA21-1) as a prognostic factor in intrahepatic cholangiocarcinoma. Ann Surg Oncol 15: 583-589, 2008.

42. Patel AH, Harnois DM, Klee GG, LaRusso NF and Gores GJ: The utility of CA19-9 in the diagnoses of cholangiocarcinoma in patients without primary sclerosing cholangitis. Am J Gastroenterol 95: 204-207, 2000.

43. Karakatsanis A, Papaconstantinou I, Gazouli M, Lyberopoulou A, Polymeneas G and Voros D: Expression of microRNAs, miR-21, miR-31, miR-122, miR-145, miR-146a, miR-200c, miR-221, miR-222, and miR-223 in patients with hepatocellular carcinoma or intrahepatic cholangiocarcinoma and its prognostic significance. Mol Carcinog 52: 297-303, 2013.

44. Nishino R, Honda M, Yamashita T, Takatori $\mathrm{H}$, Minato $\mathrm{H}$, Zen Y, Sasaki M, Takamura H, Horimoto K, Ohta T, et al: Identification of novel candidate tumour marker genes for intrahepatic cholangiocarcinoma. J Hepatol 49: 207-216, 2008.

45. Schmitz KJ, Lang H, Frey UH, Sotiropoulos GC Wohlschlaeger J, Reis H, Takeda A, Siffert W, Schmid KW and Baba HA: GNAS1 T393C polymorphism is associated with clinical course in patients with intrahepatic cholangiocarcinoma. Neoplasia 9: 159-165, 2007. 